\title{
A COMPARATIVE STUDY OF LEVOBUPIVACAINE AND RAC-BUPIVACAINE FOR CAUDAL ANALGESIA IN PAEDIATRIC SUBUMBILICAL SURGERIES
}

\author{
Leo Sundararajan¹, Prasannavani Vanamail ${ }^{2}$
}

${ }_{1}^{1}$ Associate Professor, Department of Anaesthesiology, Thanjavur Medical College and Hospital, Thanjavur, Tamilnadu.

${ }^{2}$ Consultant Anaesthesiologist, Cancer Institute, Adyar, Chennai, Tamilnadu

\section{BACKGROUND}

ABSTRACT

Safety margin of various local anaesthetics have been analysed in the context of toxicity. Many studies have shown that Levobupivacaine has a higher safety profile, but there have been very few studies demonstrating an overwhelming benefit of Levobupivacaine over racemic Bupivacaine for paediatric regional anaesthesia.

\section{MATERIALS AND METHODS}

A randomised, double-blinded study was aimed to determine the presence of clinically significant differences in the analgesic efficacy and motor blockade of Levobupivacaine and Bupivacaine for caudal block under propofol based anaesthesia in children. After obtaining Ethical Committee approval and informed written parental consent, sixty children 2 - 12 years of either sex belonging to ASA PS I - II, undergoing elective subumbilical surgeries were equally randomised and received $1 \mathrm{~mL} / \mathrm{kg}, 0.25 \%$ of either Levobupivacaine (Group L) or Bupivacaine (Group B) caudally. Intraoperatively, onset of analgesia and haemodynamic variability were noted. Caudal block was assessed using FLACC pain score (0-10), time for first rescue analgesia and motor blockade with Modified Bromage score (0 - 3). Statistical analysis was done with SPSS version 16.0. The independent ' $t$ ' test, chi-square or Fisher's exact test were used to analyse the variables. Significance was defined as ' $p$ ' value was $<0.05$.

\section{RESULTS}

Onset of analgesia was $21.68 \pm 1.28$ minutes in Group B and $26.12 \pm 1.48$ minutes in Group L, showing statistical significance (p value $=0.01$ ). BP (systolic and diastolic) was significantly lower in Group B at 25, 30, 45 and 60 minutes. FLACC pain score at recovery was $<3$ in both groups. Time for first rescue analgesia was $313.20 \pm 63.10$ minutes in Group B and $345.60 \pm 73.55$ minutes in Group $\mathrm{L}$ ( $\mathrm{p}$ value $>0.05$ ). Motor blockade at 120 minutes showed that complete recovery (score 0) was $36 \%$ higher in Group L than Group B (p value- 0.02$)$.

\section{CONCLUSION}

Onset of analgesia was delayed with Levobupivacaine. Analgesic efficacy at recovery and time for first rescue analgesia were similar in both groups. Motor blockade was lesser with Levobupivacaine at 120 minutes when compared to Bupivacaine.

\section{KEYWORDS}

Caudal Anaesthesia; Levobupivacaine; Analgesic Efficacy; Residual Motor Blockade; Bupivacaine.

HOW TO CITE THIS ARTICLE: Sundararajan L, Vanamail P. A comparative study of levobupivacaine and rac-bupivacaine for caudal analgesia in paediatric subumbilical surgeries. J. Evolution Med. Dent. Sci. 2018;7(11):1313-1317, DOI: 10.14260/jemds/2018/299

\section{BACKGROUND}

Inadequate intraoperative analgesia in children causes exaggerated stress response and results in long-term behavioural changes due to the 'rewiring' of nerve pathways. ${ }^{(1)}$ The nerves essential for transmission and perception of pain are present and functions by 24 weeks of gestation even with incomplete myelination. Unlike adults, paediatric regional anaesthetic techniques are done typically under general anaesthesia. Campbell (1933) was the first to perform caudal epidural blocks on children. The American Society of Regional Anaesthesia and Pain Medicine(2) has issued a practice advisory that is based on class I evidence, stressing the need of anaesthesia or sedation in children before giving blocks.

'Financial or Other Competing Interest': None.

Submission 31-01-2018, Peer Review 24-02-2018,

Acceptance 02-03-2018, Published 12-03-2018.

Corresponding Author:

Dr. Leo Sundararajan,

A-5, 55/2, Lotus Sivapriya Apartment,

Second Street, Rajappa Nagar,

Thanjavur-613007, Tamilnadu, India.

E-mail: leosun2000@gmail.com

DOI: $10.14260 /$ jemds $/ 2018 / 299$

\section{(c) (i) $(9)$}

Safety margin of various local anaesthetics have been analysed for systemic toxicity. Studies $(3,4,5)$ have indicated that Dextrobupivacaine to be seven-fold more potent than Levobupivacaine in blocking the potassium channel that leads to cardiotoxicity and demonstrated that Levobupivacaine has a higher safety profile. $(6,7,8)$ But there have been few studies demonstrating a clinically significant benefit to Levobupivacaine over racemic bupivacaine for paediatric regional anaesthesia.

This study was aimed to compare the analgesic efficacy and residual motor weakness of levobupivacaine with racemic bupivacaine following caudal block in paediatric subumbilical surgeries.

\section{MATERIALS AND METHODS}

After obtaining Institutional Ethical Committee approval and written informed parental consent, a double-blinded randomised controlled study was designed to compare Bupivacaine and Levobupivacaine for caudal block in paediatric elective subumbilical surgeries at Thanjavur Medical College, a state government tertiary care centre catering to rural and urban population. 
The Sample Size was calculated using Open Epi Software based on the following Assumptions-

1. Estimation was made based on the study by Jadhav PA et al, in which the difference between the groups was $40 \%$ in residual motor blockade $(70 \%$ of patients in Bupivacaine Group had residual motor blockade versus $30 \%$ in Levobupivacaine group);

2. Type I error of 0.05 ;

3. Type II error of 0.2. A minimum of twenty five patients were needed in each group.

4. Considering $10 \%$ non-compliance factor, 5 participants were added in each group. Thus, the final sample size was decided as 30 in each group.

Sixty children of 2 - 12 years and of either sex belonging to ASA-PS I-II were included. Children with known hypersensitivity, history of any active systemic illness, history of analgesic drug use, cutaneous infection or anatomical malformation at the puncture site were excluded. Randomisation was done by closed cover-lot picking method (Simple randomisation).

Two persons were involved in ensuring the blinding of the study. First person prepared the drugs based on the group and noted in a register. The second person administered caudal block, monitored the child and collected the data. The intervention each child received was revealed at the end of the study. All children were fasted for 4 - 6 hours prior to surgery. On arrival into the OT, basal vitals were recorded. Intravenous access was secured. After pre-oxygenation, child was premedicated with Glycopyrrolate $0.004 \mathrm{mg} / \mathrm{kg}$, Midazolam $0.1 \mathrm{mg} / \mathrm{kg}$ and Fentanyl $2 \mu \mathrm{g} / \mathrm{kg}$ IV. Induction was with Propofol $2 \mathrm{mg} / \mathrm{kg}$ and Lignocaine $1 \mathrm{mg}$ per $10 \mathrm{mg}$ of Propofol. After confirming proper mask ventilation, succinylcholine $2 \mathrm{mg} / \mathrm{kg}$ IV was given and child was intubated with an appropriate sized endotracheal tube (ETT) and the position was confirmed. Anaesthesia was maintained on Propofol infusion at $100 \mu \mathrm{g} / \mathrm{kg} / \mathrm{min}$ and titrated. Ventilation was assisted with $100 \%$ oxygen. Under sterile aseptic precautions and left lateral position, caudal space was identified at sacral hiatus using a 22-G needle. The study drug either Bupivacaine $0.25 \%$ (Group B) or Levobupivacaine $0.25 \%$ (Group L) was injected at the dose of $1 \mathrm{~mL} / \mathrm{kg}$ for all subumbilical surgeries.

Analgesic efficacy (primary outcome) was assessed by haemodynamic variability, pain score on recovery and time to first rescue analgesia. HR, systolic and diastolic BP and SpO2 were monitored continuously and recorded at 5 minutes interval from induction till 30 minutes and thereafter at 15 minutes interval till recovery. Intraoperative hypotension and bradycardia were planned to treat with Ephedrine for BP $<25 \%$ of baseline and Atropine $20 \mu \mathrm{g} / \mathrm{kg}$ for $\mathrm{HR}<80 / \mathrm{min}$. On awakening pain was evaluated using FLACC( 9 ) (Face, Leg, Activity, Cry, Consolability) pain scale (0-10). The scores were noted at 30 minutes interval as mild pain 0 - 3; moderate pain $4-6$ and severe pain $>6$. Time to first rescue analgesia, defined as the time to reach a FLACC score $>4$ was noted and treated with paracetamol $20 \mathrm{mg} / \mathrm{kg}$ as rectal suppository.

Secondary outcomes were onset of analgesia, recovery of residual motor blockade and adverse effects. Onset of analgesia was defined as time from caudal block to absence of either haemodynamic response $(<25 \%$ of basal) or patient movement to Allis clamp application at incision site noted. Recovery of motor blockade was evaluated using Modified
Bromage scale (0- No Motor block, 1- Can flex knee, move foot, but cannot raise leg, 2- can move foot only, 3- cannot move foot or knee) at 30 minutes interval. Children with score of 2 or 3 were classified to have motor weakness clinically. Adverse effects like vomiting was treated with Ondansetron $50 \mathrm{mcg} / \mathrm{kg}$ IV and shivering was treated with Tramadol $0.5 \mathrm{mg} / \mathrm{kg}$ IV.

Of the sixty children enrolled for the study, five from each group were abandoned on account of failure to identify caudal space, inadequate level and blood on needle insertion. The remaining fifty completed the study successfully. Statistical analysis was done with SPSS (Statistical Package for Social Sciences) version 16.0. The independent ' $t$ ' test was used for analysis of differences in haemodynamic variables and time to rescue analgesia. ASA physical status, gender, FLACC score and residual motor blockade were analysed with chi-square or Fisher's exact test. Significance was defined as 'p' value $<0.05$.

\section{RESULTS}

The distribution of Demographic data, the preoperative HR, systolic and diastolic BP and the types of surgery performed in both the groups did not show any statistically significant difference (Table 1).

Mean HR was significantly less in Group $L$ at time intervals of 15, 20, 25 and 30 (Figure 2). BP (both systolic and diastolic) was significantly lower in Group B at 25, 30, 45 and 60 minute time intervals (Figure 3 and 4).

The FLACC pain score at recovery was $<3$ in all children. Children in Group L showed a statistically significant lower pain scores from 60 to 180 minutes post-operatively (Figure 1). Time to first rescue analgesia was $313.20 \pm 63.10$ minutes in Group B and $345.60 \pm 73.55$ minutes in Group L showing insignificant ( $p$ value- 0.10 ) (Table 2).

Onset of analgesia was $21.68 \pm 1.28$ minutes in Group B and $26.12 \pm 1.48$ minutes in Group L. It was statistically significant with a ' $p$ ' value of 0.01 (Table 2 ).

The residual motor blockade was analysed in terms of frequency (percentage) of Modified Bromage score. At 120 minutes, complete recovery of blockade (score 0 ) was $36 \%$ higher in Group L compared to Group B with the ' $p$ ' value of 0.02 (Table 3). Adverse effects were comparable between groups.

\begin{tabular}{|c|c|c|c|c|}
\hline \multicolumn{2}{|c|}{ Parameters } & Group B & Group L & \begin{tabular}{|l|} 
P value \\
\end{tabular} \\
\hline \multirow{3}{*}{\begin{tabular}{|c} 
Age \\
Distribution \\
(Years) \\
\end{tabular}} & $2-5$ & $8(32 \%)$ & $8(32 \%)$ & \multirow{3}{*}{0.79} \\
\hline & $6-8$ & $9(36 \%)$ & $7(28 \%)$ & \\
\hline & $9-12$ & $8(32 \%)$ & $10(40 \%)$ & \\
\hline \multirow{2}{*}{ Gender } & Male & $13(52 \%)$ & $14(56 \%)$ & \multirow{2}{*}{0.77} \\
\hline & Female & $12(48 \%)$ & $11(44 \%)$ & \\
\hline \multirow{5}{*}{$\begin{array}{l}\text { Types of } \\
\text { Surgery }\end{array}$} & $\begin{array}{c}\text { Hypospadias } \\
\text { Repair }\end{array}$ & $4(16 \%)$ & $3(12 \%)$ & \multirow{5}{*}{0.66} \\
\hline & Herniotomy & $9(36 \%)$ & $7(28 \%)$ & \\
\hline & Orchidopexy & $1(4 \%)$ & $4(16 \%)$ & \\
\hline & Circumcision & $7(28 \%)$ & $6(24 \%)$ & \\
\hline & Others & $4(16 \%)$ & $5(20 \%)$ & \\
\hline \multicolumn{2}{|c|}{$\begin{array}{c}\text { Duration of Surgery } \\
\text { (Minutes) }\end{array}$} & $\begin{array}{c}36.92 \pm \\
23.74 \\
\end{array}$ & $\begin{array}{c}33.40 \pm \\
23.70 \\
\end{array}$ & 0.60 \\
\hline \multicolumn{2}{|c|}{ Weight (kg) } & $\begin{array}{l}20.8 \pm \\
6.45\end{array}$ & $\begin{array}{c}21.52 \pm \\
5.94\end{array}$ & 0.68 \\
\hline \multicolumn{2}{|c|}{ Height $(\mathrm{cm})$} & $\begin{array}{c}115.04 \pm \\
17.58 \\
\end{array}$ & $\begin{array}{c}113.76 \pm \\
22.60 \\
\end{array}$ & 0.82 \\
\hline \multicolumn{2}{|c|}{$\begin{array}{c}\text { Preoperative HR } \\
\text { (Beats/Minute) }\end{array}$} & $\begin{array}{c}117.84 \pm \\
9.75\end{array}$ & $\begin{array}{c}114.48 \pm \\
13.07\end{array}$ & 0.06 \\
\hline
\end{tabular}




\begin{tabular}{|c|c|c|c|}
\hline $\begin{array}{c}\text { Preoperative BP Systolic } \\
\text { (mmHg) }\end{array}$ & $\begin{array}{c}103 \pm \\
10.52\end{array}$ & $\begin{array}{c}100.68 \pm \\
9.49\end{array}$ & 0.41 \\
\hline Preoperative BP Diastolic & $60.32 \pm$ & $60.20 \pm$ & \multirow{2}{*}{0.94} \\
(mmHg) & 6.94 & 5.69 & \\
\hline \multicolumn{2}{|c|}{ Table 1. Demographic Data and Basal Vitals } \\
\hline
\end{tabular}

\begin{tabular}{|c|c|c|c|}
\hline Parameters & Bupivacaine & Levobupivacaine & $\begin{array}{c}\text { P } \\
\text { value }\end{array}$ \\
\hline $\begin{array}{c}\text { Onset of } \\
\text { Analgesia (min) }\end{array}$ & $21.68 \pm 1.28$ & $26.12 \pm 1.48$ & 0.01 \\
\hline $\begin{array}{c}\text { Block to Incision } \\
\text { Time (min) }\end{array}$ & $23.72 \pm 1.24$ & $28.12 \pm 1.51$ & 0.01 \\
\hline $\begin{array}{c}\text { Total Propofol } \\
\text { (mg/kg/min)) }\end{array}$ & $0.106 \pm 0.01$ & $0.107 \pm 0.02$ & 0.62 \\
\hline $\begin{array}{c}\text { Wakeup Time } \\
\text { (min) }\end{array}$ & $27.52 \pm 1.69$ & $25.60 \pm 1.41$ & 0.01 \\
\hline $\begin{array}{c}\text { Duration of } \\
\text { Surgery (min) }\end{array}$ & $36.92 \pm 23.74$ & $33.40 \pm 23.70$ & 0.60 \\
\hline $\begin{array}{c}\text { Duration of } \\
\text { Anaesthesia (min) }\end{array}$ & $93.16 \pm 24.95$ & $80.88 \pm 23.19$ & 0.08 \\
\hline $\begin{array}{c}\text { Time to First } \\
\text { Rescue Analgesia } \\
\text { (min) }\end{array}$ & $313.20 \pm 63.10$ & $345.60 \pm 73.55$ & 0.10 \\
\hline \multicolumn{4}{|c|}{ Table 2. Parameters Studied with Mean Values } \\
\hline
\end{tabular}

\begin{tabular}{|c|c|c|}
\hline Modified Bromage at T120 & Group B & Group L \\
\hline 0 & $10(40 \%)$ & $19(76 \%)$ \\
\hline 1 & $13(52 \%)$ & $4(16 \%)$ \\
\hline 2 & $2(8 \%)$ & $2(8 \%)$ \\
\hline \multicolumn{2}{|c|}{ Table 3. Modified Bromage Score at 120 Minutes } \\
\hline
\end{tabular}

$\mathrm{P}$ value $=0.02$

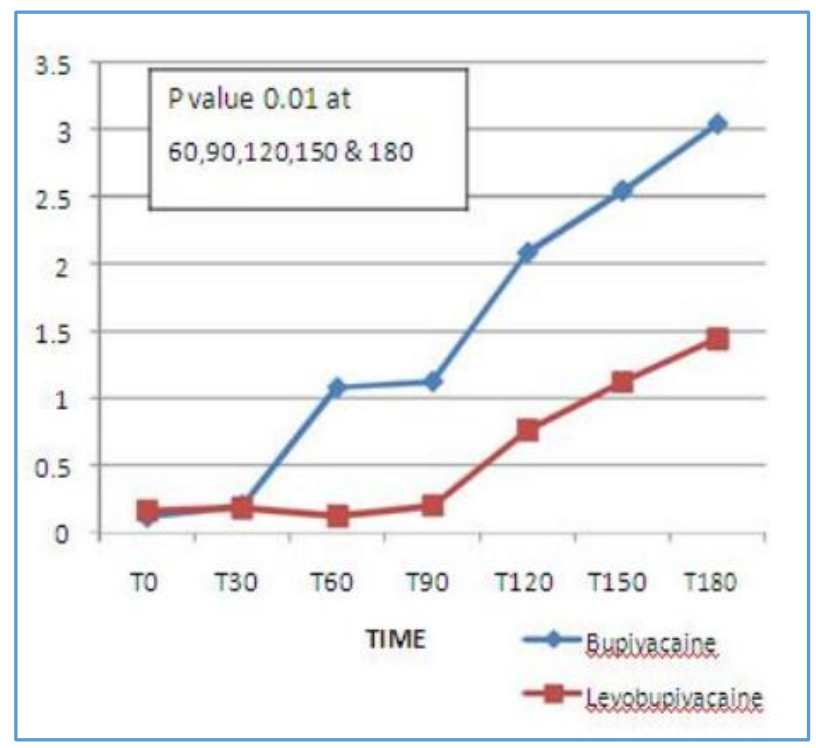

Figure 1. Mean FLACC Scores

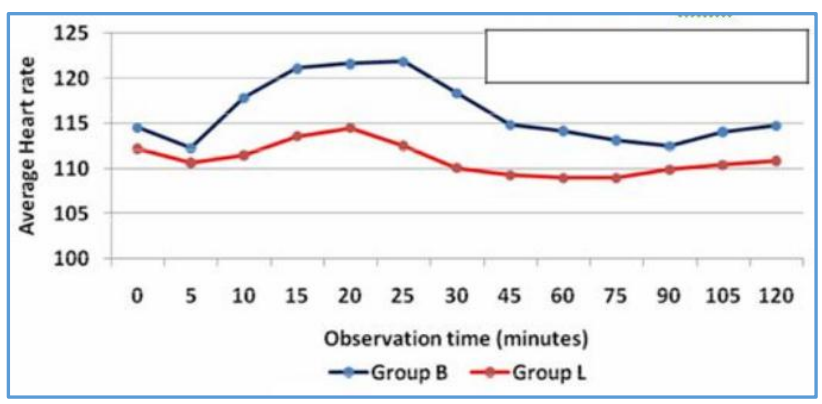

Figure 2. Intraoperative HR



Figure 3. Intraoperative Systolic BP

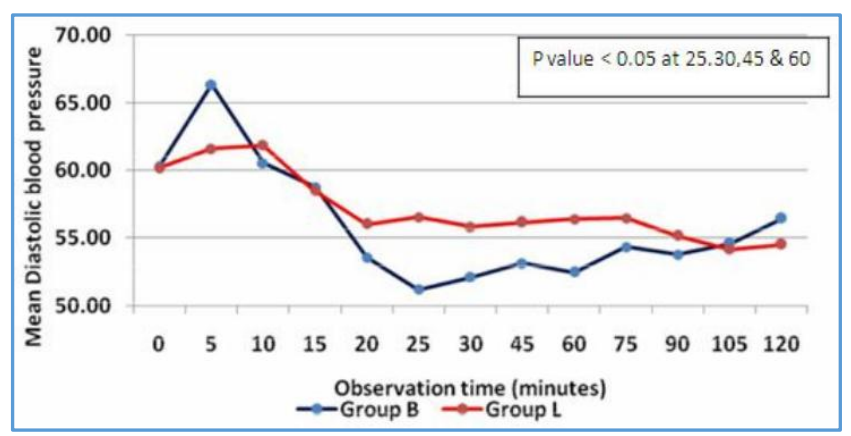

Figure 4. Intraoperative Diastolic BP

\section{DISCUSSION}

We have conducted a study on 50 children who underwent subumbilical surgeries with $1 \mathrm{~mL} / \mathrm{kg}, 0.25 \%$ of either Bupivacaine or Levobupivacaine in caudal space. Children in both groups are equally distributed with respect to age, gender, weight, height and types of surgery. The types of surgery included were commonly done day care surgical procedures in paediatric population. Thus, providing effective analgesia for a considerable duration with minimal residual blockade becomes a necessity.

Volume of drug was similar to Locatelli et al (2005)(10) and Breschan et al (2005).(11) Ivani et al (2003),(12) in his study has shown that increasing the concentration to $0.25 \%$ would prolong the duration of analgesia $(0.125 \% 60 \mathrm{~min}, 0.20 \% 118$ min, $0.25 \% 158 \mathrm{~min}$ ). The number of children with residual motor blockade in early postoperative period had a direct relationship to increasing concentrations $(0.125 \%$ : $0,0.20 \%$ : $4,0.25 \%$ : 8). Ivani et al (2002)(13) has also conducted another study with $0.25 \%$ bupivacaine, levobupivacaine and ropivacaine. They concluded that there was no significant difference in motor block among the drugs at the same concentrations. In our study, we used propofol infusion instead of inhalational agents as nitrous oxide being an emetic which would delay the discharge.(14)

In this study, mechanical stimulus was applied with Allis clamp. It has been said that it activates $\mathrm{A}$ and $\mathrm{C}$ fibres producing no tissue damage and is capable of measuring pain detection threshold with a range that is physiologically relevant.(15) In a previous study, this method showed $87 \%$ sensitivity and $98 \%$ specificity in the detection of an ineffective caudal block with different concentrations of Ropivacaine.(16)

In our study onset of analgesia was significantly delayed with Levobupivacaine than Bupivacaine (L vs. B $26.12 \pm 1.48$ vs. $21.68 \pm 1.28$, $p$ value 0.01 ). This could be explained by the delayed affinity of levo isomer to sodium channels. This is 
similar to the study by Breschan et al,(11) (L vs. B, $11.4 \pm 3.3$ vs. $10 \pm 1.8$, $\mathrm{p}$ value 0.01 ).

Wake-up time measured from the time of stopping propofol infusion to achieving a modified Aldrete score of 8 was significantly shorter with Levobupivacaine (B vs. L 27.52 \pm 1.69 vs. $25.60 \pm 1.41$, p value 0.01 ). This is similar to the study by Locatelli et al,(10) (B vs. L $29 \pm 15$ vs. $28 \pm 17$ ) who also used propofol infusion.

Analgesic efficacy (primary outcome) was assessed by intraoperative haemodynamic variability and FLACC scores at different intervals.

Heart rate was statistically higher in Group B at T15, 20, 25 and 30 minutes. Tachycardia in Group B at this interval could be explained by Bupivacaine induced hypotension.

Systolic and Diastolic BP at T25, T30, T45 and T60 were lower in Group B as compared to Group L and the difference was statistically significant. Though both drugs would cause a consistent reduction of heart contractility, the finding of less depression with Levobupivacaine lends further support to the contention that the negative inotropic effect of bupivacaine has an enantiomer-specific component.(4) None of the children required vasopressors in our study. However, a definite interpretation of these haemodynamic changes requires more invasive methods of haemodynamic and cardiac function monitor plotted against a measurement of plasma drug concentrations at specific time intervals.

The FLACC mean pain score at recovery was mild pain $<3$ in all children. Though the pain scores between the groups were below the threshold for receiving rescue analgesia, children in Group L showed a statistically significant lower pain scores from 60 to 180 minutes. This was similar to the study by Frawley et al.(17) Analysing the frequency (Percentage), at 120 minutes, all children in either group had mild (1 - 3) grade of pain score. At 180 minutes, children in Group B having moderate $(4-6)$ grade pain and hence requiring rescue analgesia were seven times higher than in Group L (28\% vs. 4\%, p value 0.02). Another study(9) found that FLACC score had a good inter-rater reliability and validity which was correlated with other pain scores and it served as a simple tool in quantifying pain in children who may not be able to verbalise the presence or severity of pain.

Time to first rescue analgesia was not significantly different in the two groups (B vs. L $313.20 \pm 63.10$ vs. 345.60 \pm 73.55 ). This is similar to the study conducted by Breschan et al,(11) (B vs. L 375 minutes vs. 320 minutes). In a similar study design with a different pain assessment scale conducted to compare $0.25 \%$ Levobupivacaine with $0.25 \%$ Ropivacaine showed the time to first analgesia request was $330.50 \pm 9.54$ and $312.67 \pm 5.56$ respectively, which is similar to the Levobupivacaine group in our study.(18)

The Modified Bromage score was used to assess the residual motor blockade from recovery till 180 minutes at 30 min interval. A study conducted with similar design for herniotomy by Jadhav PA et al(19) have shown that the incidence of residual motor blockade at wake up was $30 \%$ with levobupivacaine and $70 \%$ with bupivacaine $(p=0.004)$, whereas it was $100 \%$ in both the groups $(>1)$ in our study. This could be explained by the larger volume $(0.75 \mathrm{~mL} / \mathrm{kg}$ vs. $1 \mathrm{~mL} / \mathrm{kg}$ ) used in our study, in spite of similar duration of both surgery and anaesthesia in both studies.
At 120 minutes, score 0 (no motor block) was $36 \%$ higher in Group L compared to Group B which was statistically significant (L vs. B $76 \%$ vs. $40 \%$, p value 0.02 ). Breschan et al(11) have similar findings at 60 and 120 minutes. Probably, the use of $0.2 \%$ concentration in their study could have caused a difference at 60 minutes itself. The difference was due to $\mathrm{R}$ $(+)$ enantiomer of bupivacaine exerting a synergistic effect on binding characteristics of S (-) enantiomer of bupivacaine to the motor nerves and in their absence binding is less and effect terminates earlier.(20) Locatelli et al(10) because of the delayed surgical duration $(31 \pm 23$ minutes $)$ had a statistically significant differentiation between the groups. Modified Bromage score 0 at wakeup with Bupivacaine vs. Levobupivacaine was $28 \%$ vs. $67 \%$, ( $p=0.01)$. In spite of using similar concentrations, Frawley et al(17) could not appreciate the effect of levobupivacaine on motor weakness because of very early assessment. Locatelli et al have said that patients receiving levobupivacaine $0.25 \%$ had significantly lesser residual motor block than patients receiving $0.25 \%$ bupivacaine, ( $\mathrm{p}$ value 0.04 ). To summarise, levobupivacaine group at various time intervals showed better motor recovery state.

\section{Limitation of this Study}

In accordance with the pharmacokinetics, assessing residual motor blockade from the time of caudal injection would be ideal. In this study it was assessed from the time of wakeup which could vary with the duration of surgery, so it could influence the assessment. But the mean duration of surgery in our study was comparable between the two groups.

\section{CONCLUSION}

We conclude that Levobupivacaine has better haemodynamics compared to Bupivacaine. Analgesic efficacy by means of pain score and time to first rescue analgesia was similar in both the groups. Though onset of analgesia is delayed, residual motor blockade is lesser with Levobupivacaine.

\section{ACKNOWLEDGEMENT}

We are very much thankful to Dr. P. Vanamail, PhD, for his sincere work on Statistical Analysis.

\section{REFERENCES}

[1] Taddio A, Katz J, Ilersich AL, et al. Effect of neonatal circumcision on pain response during subsequent routine vaccination. Lancet 1997;349(9052):599-603.

[2] Bernards CM, Hadzic A, Suresh S, et al. Regional anaesthesia in anesthetized or heavily sedated patients. Reg Anesth Pain Med 2008;33(5):449-60.

[3] Chang DH, Ladd LA, Wilson KA, et al. Tolerability of large-dose intravenous levobupivacaine in sheep. Anesth Analg 2000;91(3):671-9.

[4] Bardsley H, Gristwood R, Baker H, et al. A comparison of cardiovascular effects of levobupivacaine and racbupivacaine following intravenous administration to healthy volunteers. $\mathrm{Br} \mathrm{J}$ Clin Pharmacol 1998;46(3):245-9.

[5] Heavner JE. Cardiac toxicity of local anaesthetics in the intact isolated heart model: a review. Reg Anaesth Pain Med 2002;27(6):545-55. 
[6] Tetzlaff JE. The pharmacology of local anaesthetics. Anaesthesiology Clinics of North America 2000;18(2):217-33.

[7] Valenzuela C, Delpon E, Tamkun MM, et al. Stereoselective block of a human cardiac potassium channel (Kv1.5) by bupivacaine enantiomers. Biophysical Journal 1995;69(2):418-27.

[8] Valenzuela C, Snyders DJ, Bennett PB, et al. Stereoselective block of cardiac sodium channels by bupivacaine in guinea pig ventricular myocytes. Circulation 1995;92(10):3014-24.

[9] Merkel SI, Voepel-Lewis T, Shayevitz JR, et al. The FLACC: a behavioral scale for scoring postoperative pain in young children. Pediatr Nurs 1997;23(3):293-7.

[10] Locatelli B, Ingelmo P, Sonzogni V, et al. Randomized, double-blind, phase III, controlled trial comparing levobupivacaine $0.25 \%$, ropivacaine $0.25 \%$ and bupivacaine $0.25 \%$ by the caudal route in children. British Journal of Anae. Br J Anaesth 2005;94(3):36671.

[11] Breschan C, Jost R, Krumpholz R, et al. A prospective study comparing the analgesic efficacy of levobupivacaine, ropivacaine and bupivacaine in pediatric patients undergoing caudal blockade. Paediatr Anaesth 2005;15(4):301-6.

[12] Ivani G, De Negri P, Lonnqvist PA, et al. A comparison of three different concentrations of levobupivacaine for caudal block in children. Anesthesia \& Analgesia 2003;97(2):368-71.

[13] Ivani G, De Negri P, Conio A, et al. Comparison of racemic bupivacaine, ropivacaine and levobupivacaine for pediatric caudal anaesthesia: effects on postoperative analgesia and motor block. Regional Anaesthesia and Pain Med 2002;27(2):157-61.
[14] Tramer MR, Moore A, McQuay H. Omitting nitrous oxide in general anaesthesia: meta-analysis of intraoperative awareness and postoperative emesis in randomized controlled trials. British Journal of Anaesthesia 1996;76(2):186-93.

[15] Curatolo M, Petersen-Felix S, Arendt-Nielsen L. Sensory assessment of regional anaesthesia in humans. A review of methods and applications. Anaesthesiology 2000;93(6):1517-30.

[16] Ingelmo PM, Locatelli BG, DiMarco S, et al. Does general anaesthesia affect regional anaesthesia quality? Double blind randomized controlled trial evaluating the effects of intravenous and balanced anaesthesia on caudal ropivacaine pediatric block. Eur J Anaesth 2003;20(Suppl 29):101.

[17] Frawley GP, Downie S, Huang GH. Levobupivacaine caudal anaesthesia in children: a randomized doubleblind comparison with bupivacaine. Paediatric Anaesthesia 2006;16(7):754-60.

[18] Praveen P, Remadevi R, Pratheeba N. Caudal epidural analgesia in pediatric patients: comparison of $0.25 \%$ levobupivacaine and $0.25 \%$ ropivacaine in terms of motor blockade and postoperative analgesia. Anesth Essays Res 2017;11(1):223-7.

[19] Jadhav PA, Malde AD. Comparison of levobupivacaine $0.25 \%$ and bupivacaine $0.25 \%$ for caudal analgesia in children undergoing herniotomy. Paediatric Anesthesia and Critical Care Journal (PACCJ) 2017;5(2):66-73.

[20] Trachez MM, Zapta-Sudo G, Moreira OR, et al. Motor nerve blockade potency and toxicity of non-racemic bupivacaine in rat. Acta Anaesthesiol Scand 2005;49(1):66-71. 